\title{
Ablation of prion protein immunoreactivity by heating in saturated
} calcium hydroxide

\author{
Justin J Greenlee*1, Eric M Nicholson*1, Amir N Hamir ${ }^{1}$, Gary P Noyes², \\ Mark T Holtzapple ${ }^{3}$ and Marcus E Kehrli Jr ${ }^{1}$
}

\begin{abstract}
Address: '1irus and Prion Diseases of Livestock Research Unit, National Animal Disease Center, USDA, Agricultural Research Service, 2300 Dayton Avenue, Ames, IA, USA, 50010, 2Oceaneering Space Systems, Houston, TX, USA 77058 and ${ }^{3}$ Department of Chemical Engineering, Texas A\&M University, College Station, TX, USA 77843

Email: Justin J Greenlee* - justin.greenlee@ars.usda.gov; Eric M Nicholson* - eric.nicholson@ars.usda.gov; Amir N Hamir - amir.hamir@ars.usda.gov; Gary P Noyes - gnoyes@oceaneering.com; Mark T Holtzapple - mth4500@chemail.tamu.edu; Marcus E Kehrli - marcus.kehrli@ars.usda.gov

* Corresponding authors
\end{abstract}

Published: 28 October 2008

BMC Research Notes 2008, 1:99 doi:10.1 186/1756-0500-1-99

This article is available from: http://www.biomedcentral.com/1756-0500/1/99

(c) 2008 Greenlee et al; licensee BioMed Central Ltd.

This is an Open Access article distributed under the terms of the Creative Commons Attribution License (http://creativecommons.org/licenses/by/2.0), which permits unrestricted use, distribution, and reproduction in any medium, provided the original work is properly cited.
Received: 23 April 2008

Accepted: 28 October 2008

\begin{abstract}
Background: Prions, the infectious agents that cause transmissible spongiform encephalopathies (TSEs), are relatively resistant to destruction by physical, enzymatic, and chemical treatments. Hydrolysis in boiling saturated calcium hydroxide (limewater) utilizes inexpensive chemicals to digest protein components of offal. The purpose of this work was to determine if incubating brain material from scrapie-infected sheep in near-boiling saturated calcium hydroxide solution $\left(\mathrm{Ca}(\mathrm{OH})_{2}\right)$ would abolish immunoreactivity of the infectious prion (PrPsc) as determined by western blot.
\end{abstract}

Findings: After incubating for as few as 10 minutes in saturated calcium hydroxide at $99^{\circ} \mathrm{C}$, immunoreactivity of protease resistant bands by western blot analysis is completely lost.

Conclusion: Boiling in limewater may offer an alternative for disposal of carcasses and enable alternative uses for rendered products from potentially infected carcasses.

\section{Background}

Scrapie in sheep, bovine spongiform encephalopathy (BSE), chronic wasting disease (CWD) of deer and elk, and Creutzfeldt-Jakob disease in humans are chronic neurodegenerative diseases associated with the accumulation of the protease-resistant, disease-associated isoform of the prion protein $(\mathrm{PrPSc})$ in selected regions of the central nervous system. PrPsc is relatively resistant to inactivation by standard decontamination procedures [1] and can remain infectious after undergoing sterilization procedures under high pressure, treatment with disinfectants, or exposure to dry heat.[2]
The host of any particular prion disease determines the potential distribution of $\mathrm{PrPSc}^{\mathrm{S}}$ in the tissues. Brain, spinal cord, and distal ileum and in some species, peripheral lymphoid tissues contain infectious material ( $\mathrm{PrPsc}$ ). Removal, handling, and disposal of tissue with the potential to harbor infectious $\mathrm{PrPSc}^{\mathrm{Sc}}$ represent a challenge to the meatpacking and by-product industries. Efficient methods of inactivating potentially infectious material are needed.

A number of procedures have been described to decontaminate surfaces or reusable medical devices, [3-7] but 
few of these methods are appropriate for decontamination of large volumes of animal tissue from TSE-infected animals. Chemical means of inactivation such as concentrated hypochlorite (bleach) solutions or sodium hydroxide solution can damage equipment, cause respiratory irritation in workers exposed to fumes, pose problems with disposal, or may not be appropriate for processing large amounts of material. Disposal of large volumes of chemically treated material may present problems for some municipal sewage systems. High-pressure and temperature methods of inactivation [3] or reducing infectivity[8] of tissues and proteolytic digestion by enzymes secreted by thermophylic bacteria[9] have not been demonstrated to be effective on a large scale.

Methods for detecting abnormal prion in meat and bone meal (MBM) are under development,[10] but methods that inactivate abnormal prions and leave material with by-product value (concentrated amino acids, feed additive, fertilizer, etc.) may be more desirable. Incineration can inactivate the agent,[2] but precludes any recovery or reuse of raw material.

Inexpensive, effective means of inactivating prions in offal are needed for safe disposal of carcasses and to ensure the safety of animal by-products if used as a feed source. Ultimately, the success of any potential method of inactivation must be measured by comparing infectivity in cell cultures[11] or animal models of prion disease, but western blot can be used to screen for unfolding or denaturation of PrPsc, which would result in a loss of reactivity with prion-specific antibodies. The purpose of this study was to determine if incubating brain material from scrapie-infected sheep in near-boiling saturated calcium hydroxide solution would abolish immunoreactivity of the infectious prion $(\mathrm{PrPSc})$ as determined by western blot.

\section{Methods}

\section{Preparation of brain material}

Brain immunoreactive for $\mathrm{PrPSc}$ by immunohistochemistry and western blot from intracerebrally inoculated sheep or brain from scrapie-free control animals[12] was homogenized at a final concentration of $40 \%(\mathrm{w} / \mathrm{v})$ in 10 $\mathrm{mM}$ Tris $5 \mathrm{mM} \mathrm{MgCl}_{2}$, $\mathrm{pH} 7.5$ using a tissue homogenizer (Powergen 125 homogenizer, Fisher Scientific) with disposable probe. Secondly, ultrasonic dismembranation (Fisher Scientific Model 500 Ultrasonic Dismembrator, Fisher Scientific) was performed for four 30-second intervals in an ice bath with brief vortex mixing between sonication. The samples were then centrifuged at 2,000 $\times \mathrm{g}$ for 2 minutes at room temperature. The supernatant was then treated with $100 \mathrm{U} / \mathrm{mL}$ benzonase (Novagen) at $37^{\circ} \mathrm{C}$ for 1 hour. The material was used immediately for the inactivation experiments or frozen at $-80^{\circ} \mathrm{C}$ for later use.

\section{Calcium Hydroxide $\left(\mathrm{Ca}(\mathrm{OH})_{2}\right.$ treatment}

The $40 \%$ brain homogenates were diluted to a final concentration of $10 \%(\mathrm{w} / \mathrm{v})$ brain in saturated $\mathrm{Ca}(\mathrm{OH})_{2}$ containing excess insoluble $\mathrm{Ca}(\mathrm{OH})_{2}$. Samples of $10 \%(\mathrm{w} / \mathrm{v})$ brain homogenate in $10 \mathrm{mM}$ Tris $5 \mathrm{mM} \mathrm{MgCl}_{2}$, $\mathrm{pH} 7.5$ were processed in parallel to those homogenized in saturated $\mathrm{Ca}(\mathrm{OH})_{2}$ to serve as a heat-only control. All samples except from the zero timepoint were placed at $99^{\circ} \mathrm{C}$ for incubation. The zero timepoint sample and samples measured at subsequent timepoints were neutralized by a 1:6.9 dilution into $1 \mathrm{M}$ Tris- $\mathrm{HCl}$ to stop the reaction. Icecold acetone (4 volumes) was added to each sample, and samples were then placed at $-20^{\circ} \mathrm{C}$ for at least 1 hour.

\section{Preparation of samples and analysis by western blot}

Following incubation at $-20^{\circ} \mathrm{C}$ for 1 hour, the calcium hydroxide treated samples were centrifuged at 13,000 $\times \mathrm{g}$ for 10 minutes at room temperature. The supernatant was discarded and the protein pellet was allowed to air dry. Once dry, the pellet was dissolved in SDS-PAGE sample buffer such that $1.2 \mathrm{mg}$ tissue equivalent (assuming 100\% yield) was loaded on the gel. Positive and negative scrapie control samples were homogenized in $10 \mathrm{mM}$ Tris- $\mathrm{HCl} 5$ $\mathrm{mM} \mathrm{MgCl}{ }_{2} \mathrm{pH} 7.5$ and loaded on a gel at $\sim 1 \mathrm{mg}$ tissues equivalent in SDS-PAGE sample buffer without treatment or after 240 minutes at $99^{\circ} \mathrm{C}$. For the control samples, proteinase K (USB) was added to a final concentration of $80 \mu \mathrm{g} / \mathrm{ml}$; digestion was conducted at $37^{\circ} \mathrm{C}$ for 1 hour and stopped by the addition of Pefabloc (Roche Diagnostics) to a final concentration of $0.1 \mathrm{mg} / \mathrm{mL}$.

For SDS-PAGE and western blot, a 4-20\% commercially prepared SDS-PAGE gel was loaded and run according to the manufacturer's instructions, blotted to a polyvinylidene difluoride (PVDF) membrane (GE Healthcare) and blocked with $3 \%$ bovine serum albumin. Western blot detection was conducted using mouse anti-PrP monoclonal antibody P4 (R-Biopharm AG), which targets to amino acids $89-104$ of the ovine prion protein sequence,[13] at a $1: 10,000$ dilution $(0.1 \mu \mathrm{g} / \mathrm{mL})$ as the primary antibody. Western blots were repeated using monoclonal antibody F99/97.6.1, which targets residues 220-225 of ovine prion protein sequence.[14] A biotinylated sheep anti-mouse secondary antibody at $0.05 \mu \mathrm{g} /$ $\mathrm{ml}$ and a streptavidin-horseradish peroxidase (HRP) conjugate (GE Healthcare) were used according to the manufacturer's instructions in conjunction with the ECL Plus detection system (GE Healthcare) and imaged using a Kodak Image Station In-Vivo F. Primary antibody incubations were conducted with the membrane at either room temperature for 1 hour or $4^{\circ} \mathrm{C}$ overnight ( $\geq 12$ hours). Secondary antibody and streptavidin-HRP conjugate incubations were conducted at room temperature for 1 hour. Band intensity was determined using Kodak Molecular Imaging software. 


\section{Results and discussion}

Scrapie-positive and scrapie-negative samples were confirmed based upon the presence or absence, respectively, of proteinase K-resistant PrP (Figure 1). For both scrapiepositive and scrapie-negative samples, $\operatorname{PrP}$ is clearly visible in the first sample taken after dilution into saturated $\mathrm{Ca}(\mathrm{OH})_{2}$, however, after only 10 minutes there is virtually no detectable PrP in either the scrapie-positive or scrapienegative samples (Figure 2) on a western blot. Analysis of the western blot indicates that greater than $95 \%$ of all detectable $\operatorname{PrP}$ is hydrolyzed in the first 10 minutes. Samples homogenized in $10 \mathrm{mM}$ Tris- $\mathrm{HCl} 5 \mathrm{mM} \mathrm{MgCl}_{2} \mathrm{pH}$ 7.5 remained immunoreactive after 240 minutes at $99^{\circ} \mathrm{C}$ (results not shown).

As the infectious agent, reduction in PrPSc levels is strongly suggestive of reduced infectivity. However, $\mathrm{PrPsc}$ is detected indirectly via western blot and disruption of antibody-PrPScinteractions for which there would be no corresponding reduction in infectivity could be one potential explanation for lack of immunoreactivity. Western blots were performed with multiple antibodies with different binding epitopes to assure that lack of immunoreactivity was not due to loss of an epitope at a single site. Failure to reduce $\mathrm{PrPSc}$ levels while reducing infectivity is much less likely.[15]

Base-catalyzed hydrolysis using sodium hydroxide at concentrations $\geq 1 \mathrm{~N}$ is an accepted means of decontamination of PrPsc-contaminated material.[16] Reports indicate that even this fails to completely inactivate some PrPSc isolates.[17] Failures may be more a result of the consump-

\section{$\begin{array}{llllll}1 & 2 & 3 & 4 & 5 & 6\end{array}$}

\section{0 \\ 31.0

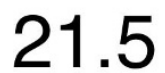

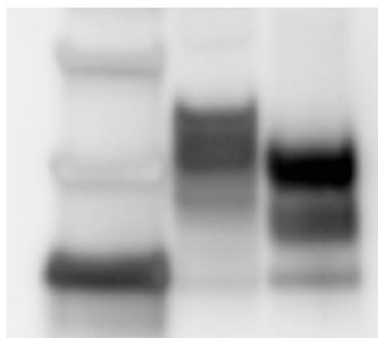

\section{Figure I}

Western blot of non-treated brain homogenates. Representative western blots of scrapie-positive and scrapienegative sheep brain homogenates. Lane I-Molecular weight marker; lane 2-Scrapie-positive brain without proteinase $\mathrm{K}$ digestion; lane 3-Scrapie-positive brain treated with proteinase K; lane 4-Blank; lane 5-Scrapie-negative brain without proteinase $\mathrm{K}$ digestion; lane 6-scrapie-negative brain with proteinase $\mathrm{K}$ digestion. Only the scrapie-positive brain homogenate exhibits proteinase $\mathrm{K}$ resistance.

\section{$\begin{array}{llllllll}1 & 2 & 3 & 4 & 5 & 6 & 7 & 8\end{array}$}
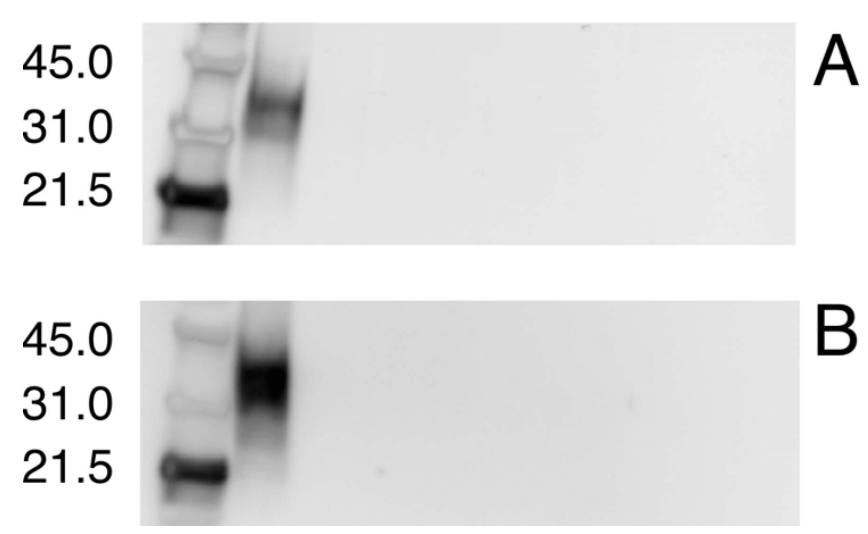

Figure 2

Western blot after calcium hydroxide treatment. Western blot analysis of calcium hydroxide treatment of scrapie-negative $(A)$ and scrapie-positive (B) sheep brain homogenate. For both, Lane I-molecular weight marker; lane 2-0 minutes; lane 3-10 minutes; lane 4-20 minutes; lane 530 minutes; lane 6-60 minutes; lane 7-120 minutes; lane 8240 minutes. PrP immunoreactivity is abolished in scrapiepositive samples after 10 minutes treatment with calcium hydroxide.

tion of hydroxide ion in the hydrolysis than an inability of $2 \mathrm{~N} \mathrm{NaOH}$ to hydrolyze PrPsc. The pH of $2 \mathrm{~N} \mathrm{NaOH}$ is greater than 14 . In contrast, saturated $\mathrm{Ca}(\mathrm{OH})_{2}$ is nearer $\mathrm{pH} 12.5$, which is still sufficient to rapidly hydrolyze peptide bonds. As the hydroxide ions are consumed in the case of $\mathrm{NaOH}$, the $\mathrm{pH}$ of the solution would drop; however, using a slurry of saturated $\mathrm{Ca}(\mathrm{OH})_{2}$ solution and insoluble $\mathrm{Ca}(\mathrm{OH})_{2}$ the hydroxide ion concentration and thus the $\mathrm{pH}$ is readily maintained. Additionally, $\mathrm{Na}^{+}$ions are poorly tolerated in feed, whereas $\mathrm{Ca}^{2+}$ ions are much more readily tolerated. Thus, although $\mathrm{Ca}(\mathrm{OH})_{2}$, is a weaker base than the often-used $\mathrm{NaOH}$ it offers some practical advantages to prion inactivation on an industrial scale for the purposes of producing a safe, alternative byproduct.

New methods of prion inactivation for application to offal would reduce complications with carcass disposal and assure safety of rendered materials used as an animal feed source. Immunoassay alone is not sufficient to evaluate the efficacy of a particular method of inactivation [11] as removal of all immunoreactive $\mathrm{PrPSc}^{\mathrm{PS}}$ correlates poorly with levels of infectivity measured by bioassay. Animal inoculations appear to be a standardizable method for the evaluation of prion inactivation, but a 15month incubation period is required to guarantee total absence of infectivity.[3] Results of this study demonstrate the potential for heating in near-boiling saturated 
$\mathrm{Ca}(\mathrm{OH})_{2}$ as a method of PrPSc inactivation with practical and safety advantages to the handling of the hydrolysate. However, confirmation of loss of infectivity requires bioassay or cell culture infectivity studies as loss of immunoreactivity in $\mathrm{WB}$ is not equivalent to loss of infectivity. Bioassay using inoculum treated with heating in saturated calcium hydroxide is currently underway. Because strain differences to some methods of inactivation have been demonstrated,[6] it may be necessary to pursue inactivation studies using material derived from cattle with BSE and cervids with CWD.

\section{Competing interests}

Gary Noyes and Mark Holtzapple are named as co-inventors on a U.S. Patent Application of the boiling-saturatedcalcium-hydroxide protein-depolymerization process. Neither has any stock or ownership in the company that has licensed the patent from Texas A\&M University.

\section{Authors' contributions}

JG, EN, MH, GN, and MK conceived of the idea for this research. JG and EN designed the experiments, analyzed and interpreted data, and wrote the manuscript. AH provided tissues and reagents and critically reviewed the manuscript. MK supervised data collection and reviewed the manuscript. All the authors have read and approved the final manuscript.

\section{Acknowledgements}

The authors thank Leisa Mandell and Semakaleng Lebepe-Mazur for providing technical support to this project. Mention of trade names or commercial products in this article is solely for the purpose of providing specific information and does not imply recommendation or endorsement by the U.S. Department of Agriculture.

\section{References}

I. Taylor DR, Hooper NM: The prion protein and lipid rafts (Review). Mol Membr Biol 2006, 23(I):89-99.

2. Brown P, Rau EH, Johnson BK, Bacote AE, Gibbs CJ Jr, Gajdusek DC: New studies on the heat resistance of hamster-adapted scrapie agent: threshold survival after ashing at $\mathbf{6 0 0}$ degrees C suggests an inorganic template of replication. Proc Natl Acad Sci USA 2000, 97(7):34|8-342।.

3. Vadrot C, Darbord JC: Quantitative evaluation of prion inactivation comparing steam sterilization and chemical sterilants: proposed method for test standardization. J Hosp Infect 2006, 64(2): | $43-\mid 48$.

4. Fichet G, Comoy E, Duval C, Antloga K, Dehen C, Charbonnier A, McDonnell G, Brown P, Lasmezas Cl, Deslys JP: Novel methods for disinfection of prion-contaminated medical devices. Lancet 2004, 364(9433):52I-526.

5. Jackson GS, McKintosh E, Flechsig E, Prodromidou K, Hirsch P, Linehan J, Brandner S, Clarke AR, Weissmann C, Collinge J: An enzymedetergent method for effective prion decontamination of surgical steel. J Gen Virol 2005, 86(Pt 3):869-878.

6. Peretz D, Supattapone S, Giles K, Vergara J, Freyman $Y$, Lessard $P$, Safar JG, Glidden DV, McCulloch C, Nguyen HO, et al:: Inactivation of prions by acidic sodium dodecyl sulfate. J Virol 2006, 80(I):322-33I.

7. Kasermann F, Kempf C: Sodium hydroxide renders the prion protein PrPSc sensitive to proteinase K. J Gen Virol 2003, 84(Pt II):3173-3176.

8. Brown P, Meyer R, Cardone F, Pocchiari M: Ultra-high-pressure inactivation of prion infectivity in processed meat: a practi- cal method to prevent human infection. Proc Natl Acad Sci USA 2003, I00(10):6093-6097.

9. Tsiroulnikov K, Rezai H, Bonch-Osmolovskaya E, Nedkov P, Gousterova A, Cueff V, Godfroy A, Barbier G, Metro F, Chobert JM, et al.: Hydrolysis of the amyloid prion protein and nonpathogenic meat and bone meal by anaerobic thermophilic prokaryotes and streptomyces subspecies. I Agric Food Chem 2004, 52(20):6353-6360.

10. Murayama Y, Yoshioka M, Horii H, Takata M, Miura K, Shinagawa M: Specific detection of prion antigenic determinants retained in bovine meat and bone meal by flow microbead immunoassay. J Appl Microbiol 2006, I 0 I (2):369-376.

II. Solassol J, Arlotto M, Lehmann S: Detection of prion after decontamination procedures: comparative study of standard Western blot, filter retention and scrapie-cell assay. J Hosp Infect 2004, 57(2): 156-161.

12. Hamir AN, Kunkle RA, Richt JA, Miller JM, Cutlip RC, Jenny AL: Experimental transmission of sheep scrapie by intracerebral and oral routes to genetically susceptible Suffolk sheep in the United States. J Vet Diagn Invest 2005, I 7(I):3-9.

13. Hardt M, Baron T, Groschup MH: A comparative study of immunohistochemical methods for detecting abnormal prion protein with monoclonal and polyclonal antibodies. J Comp Pathol 2000, I 22(I):43-53.

14. O'Rourke KI, Baszler TV, Besser TE, Miller JM, Cutlip RC, Wells GA, Ryder SJ, Parish SM, Hamir AN, Cockett NE, et al.: Preclinical diagnosis of scrapie by immunohistochemistry of third eyelid lymphoid tissue. J Clin Microbiol 2000, 38(9):3254-3259.

15. Triantis J, Dennis MM, Salman MD, Gould DH: Effect of time and temperature on PrPCWD immunoreactivity as evidenced by Western blot. I Vet Diagn Invest 2007, I 9(4):389-39I.

16. Richmond JY, McKinney RW, Centers for Disease Control (U.S.), National Institutes of Health (U.S.): Biosafety in microbiological and biomedical laboratories. 4th edition. Washington: U.S. G.P.O.: For sale by the Supt. of Docs., U.S. G.P.O.; 1999.

17. Taylor DM: Inactivation of transmissible degenerative encephalopathy agents: A review. Vet J 2000, I59(I):10-17.
Publish with Bio Med Central and every scientist can read your work free of charge

"BioMed Central will be the most significant development for disseminating the results of biomedical research in our lifetime. "

Sir Paul Nurse, Cancer Research UK

Your research papers will be:

- available free of charge to the entire biomedical community

- peer reviewed and published immediately upon acceptance

- cited in PubMed and archived on PubMed Central

- yours - you keep the copyright
BioMedcentral 